\title{
Kidney Disease and Hypertension in Pregnancy
}

\section{Phyllis August}

K

idney disease and hypertensive disorders in pregnancy are discussed. Pregnancy in women with kidney disease is associated with significant complications when renal function is impaired and hypertension predates pregnancy. When renal function is well preserved and hypertension absent, the outlook for both mother and fetus is excellent. The basis for the close interrelationship between reproductive function and renal function is intriguing and suggests that intact renal function is necessary for the physiologic adjustments to pregnancy, such as vasodilation, lower blood pressure, increased plasma volume, and increased cardiac output.

The renal physiologic adjustments to pregnancy are reviewed, including hemodynamic and metabolic alterations. The common primary and secondary renal diseases that may occur in pregnant women also are discussed. Some considerations for the management of end-stage renal disease in pregnancy are given.

$\mathrm{H}$ ypertensive disorders in pregnancy are far more common than is renal disease. Almost $10 \%$ of all pregnancies are complicated by either preeclampsia, chronic hypertension, or transient hypertension. Preeclampsia is of particular interest because it is associated with life-threatening manifestations, including seizures (eclampsia), renal failure, coagulopathy, and rarely, stroke. Significant progress has been made in our understanding of some of the pathophysiologic manifestations of preeclampsia; however, the cause of this disease remains unknown. The diagnostic categories of hypertension in pregnancy, pathophysiology of preeclampsia, and important principles of prevention and treatment also are reviewed. 


\section{Anatomic Changes in the Kidney During Pregnancy}

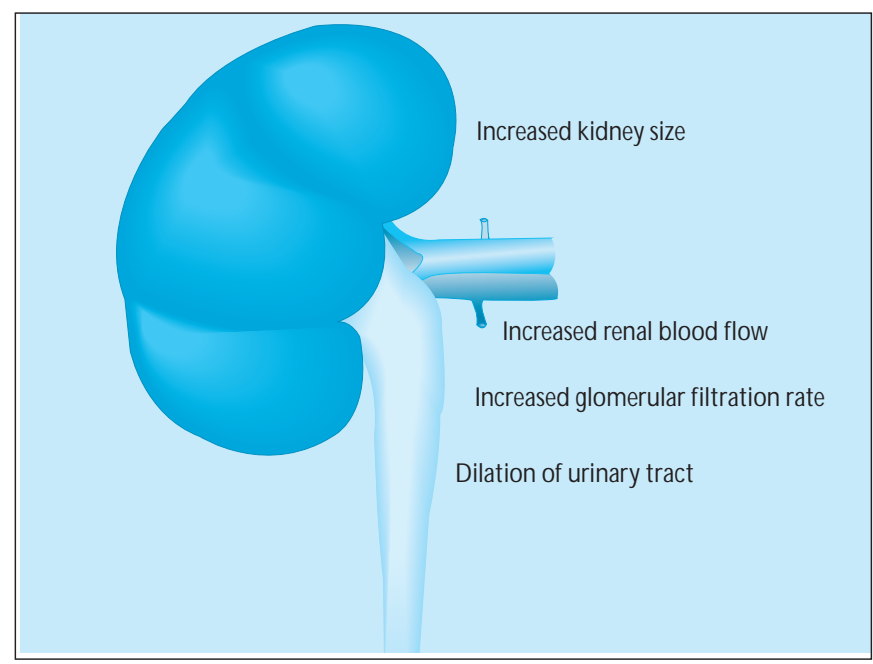

\section{FIGURE 10-1}

A natomic changes in the kidney during pregnancy. During pregnancy, kidney size increases by about $1 \mathrm{~cm}$. M ore striking are the changes in the urinary tract. The calyces, renal pelvis, and ureters dilate. The dilation is more marked on the right side than the left and is apparent as early as the first trimester. H ormonal mechanisms and mechanical obstruction are responsible. Intravenous pyelography may demonstrate the iliac sign in which ureteral dilation terminates at the level of the pelvic brim where the ureter crosses the iliac artery. U reteral dilation and urinary stasis contribute to the increased incidence of asymptomatic bacteriuria and pyelonephritis in pregnancy.

\section{Changes in Renal Function During Pregnancy}

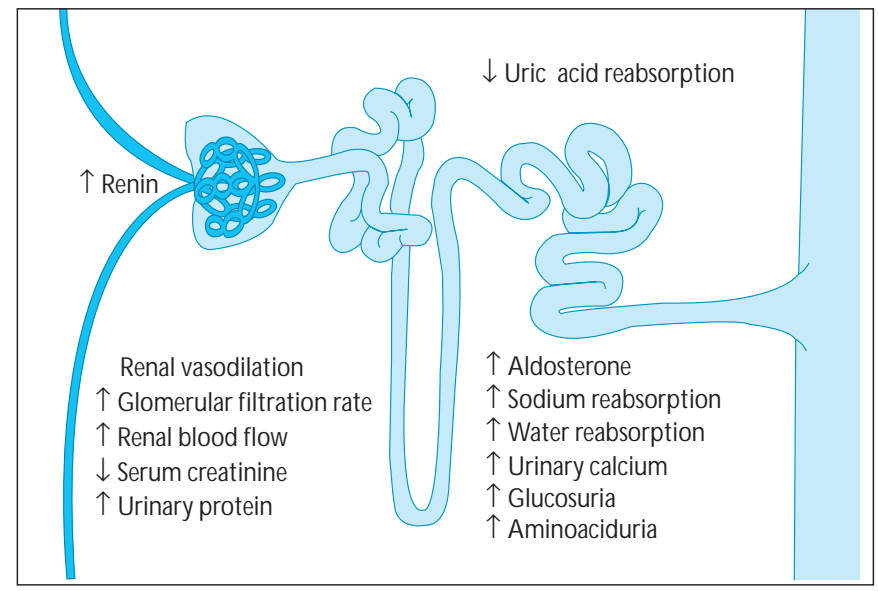

\section{FIGURE 10-2}

Changes in renal function during pregnancy. $M$ arked renal hemodynamic changes are apparent by the end of the first trimester. Both the glomerular filtration rate (GFR) and effective renal plasma flow (ERPF) increase by $50 \%$. ERPF probably increases to a greater extent, and thus, the filtration fraction is decreased during early and mid pregnancy. $M$ icropuncture studies performed in animals suggest the basis for the increase in GFR is primarily the increase in glomerular plasma flow [1]. The average creatinine level and urea nitrogen concentration are slightly lower than in pregnant women than in those who are not pregnant $(0.5 \mathrm{mg} / \mathrm{d}$ and 9 $\mathrm{mg} / \mathrm{dL}$, respectively). The increased filtered load also results in increased urinary protein excretion, glucosuria, and aminoaciduria. The uric acid clearance rates increase to a greater extent than does the GFR. H ypercalciuria is a result of increased GFR and of increases in circulating 1,25-dihydroxy-vitamin $D_{3}$ in pregnancy (absorptive hypercalciuria). The renin-angiotensin system is stimulated during gestation, and cumulative retention of approximately $950 \mathrm{mEq}$ of sodium occurs. This sodium retention results from a complex interplay between natriuretic and antinatriuretic stimuli present during gestation [2]. 


\section{Serum Electrolytes in Pregnancy}

A Altered osmoregulation: $\downarrow$ Serum sodium and $\downarrow$ Posm with $\downarrow$ Osmotic Threshold for the argenine vasopressin release and thirst

\section{B Serum chloride levels are unchanged compared with women who are not pregnant}

\begin{tabular}{l|l}
$\mathrm{Na}^{+}$ & $\mathrm{Cl}^{-}$ \\
$136 \mathrm{mEq} / \mathrm{L}$ & $104 \mathrm{mEq} / \mathrm{L}$ \\
\hline $3.7 \mathrm{mEq} / \mathrm{L}$ & $\begin{array}{l}20 \mathrm{mEq} / \mathrm{L} \\
\mathrm{HCO}_{3}\end{array}$ \\
$\mathrm{~K}^{+}$ &
\end{tabular}

C Mild hypokalemia may be observed due to $\uparrow$ glomerular filtration rate, $\uparrow$ urine flow, and $\uparrow$ aldosterone
D Mild respiratory alkalosis is associated with small decreases in plasma bicarbonate

\section{FIGURE 10-3}

Serum electrolytes in pregnancy. A, During normal gestation, serum osmolality decreases by $10 \mathrm{mosm} / \mathrm{L}$ and serum sodium $\left(\mathrm{N} \mathrm{a}^{+}\right)$decreases by $5 \mathrm{mEq} / \mathrm{L}$. A resetting of the osmoreceptor system occurs, with decreased osmotic thresholds for both thirst and vasopressin release [3]. B, Serum chloride $\left(\mathrm{Cl}^{-}\right)$levels essentially are unchanged during pregnancy. C, Despite significant increases in aldosterone levels during pregnancy, in most women serum potassium $\left(\mathrm{K}^{+}\right)$levels are either normal or, on average, $0.3 \mathrm{mEq} / \mathrm{L}$ lower than are values in women who are not pregnant [4]. The ability to conserve potassium may be a result of the elevated progesterone in pregnancy [5]. D, Arterial $\mathrm{pH}$ is slightly increased in pregnancy owing to mild respiratory alkalosis. The hyperventilation is believed to be an effect of progesterone. Plasma bicarbonate $\left(\mathrm{HCO}_{3}^{-}\right)$concentrations decrease by about $4 \mathrm{mEq} / \mathrm{L}$ [6].

\section{Blood Pressure and the Renin-Aldosterone System in Pregnancy}

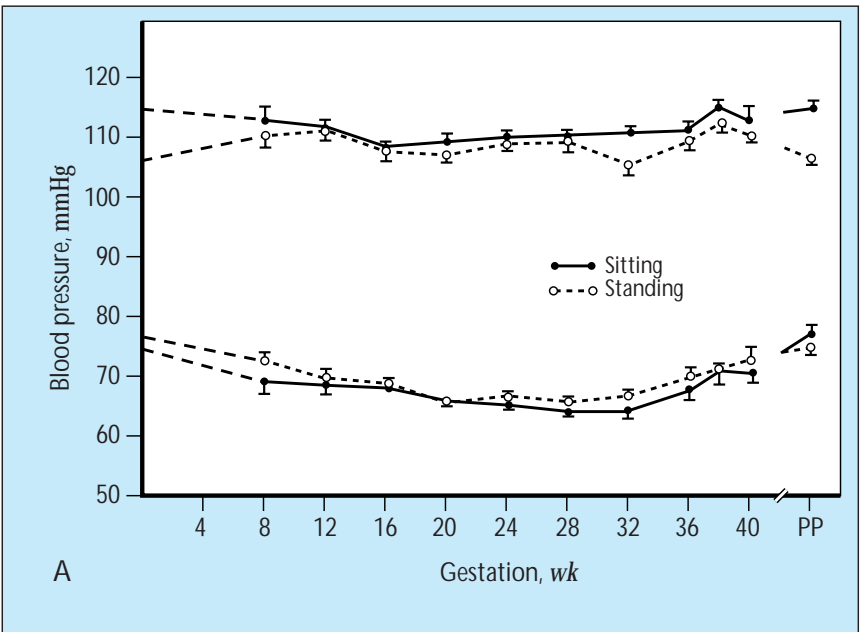

\section{FIGURE 10-4}

Blood pressure and the renin-aldosterone system in pregnancy. $\mathrm{N}$ ormal pregnancy is associated with profound alterations in cardiovascular and renal physiology. These alterations are accompanied by striking adjustments of the renin-angiotensinaldosterone system. A, Blood pressure and peripheral vascular resistance decrease during normal gestation. The decrease in blood pressure is apparent by the end of the first trimester of

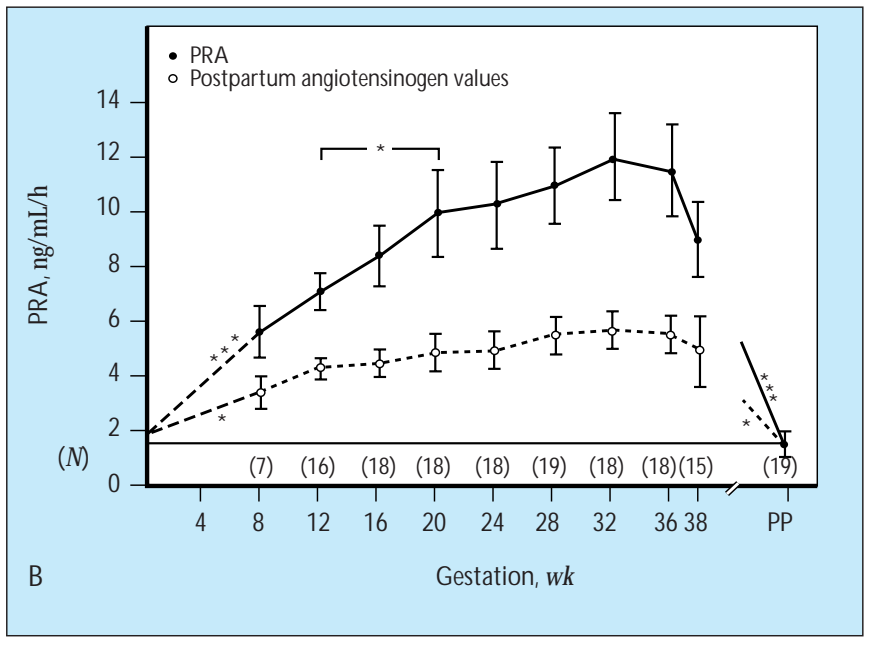

pregnancy and often approaches prepregnancy levels at term. B, D espite the decrease in blood pressure, plasma renin activity (PRA) increases during the first few weeks of pregnancy; on average, close to a fourfold increase in PRA occurs by the end of the first trimester, with additional increases until at least 20 weeks. The source of the increased renin is thought to be the maternal renal release of renin. 


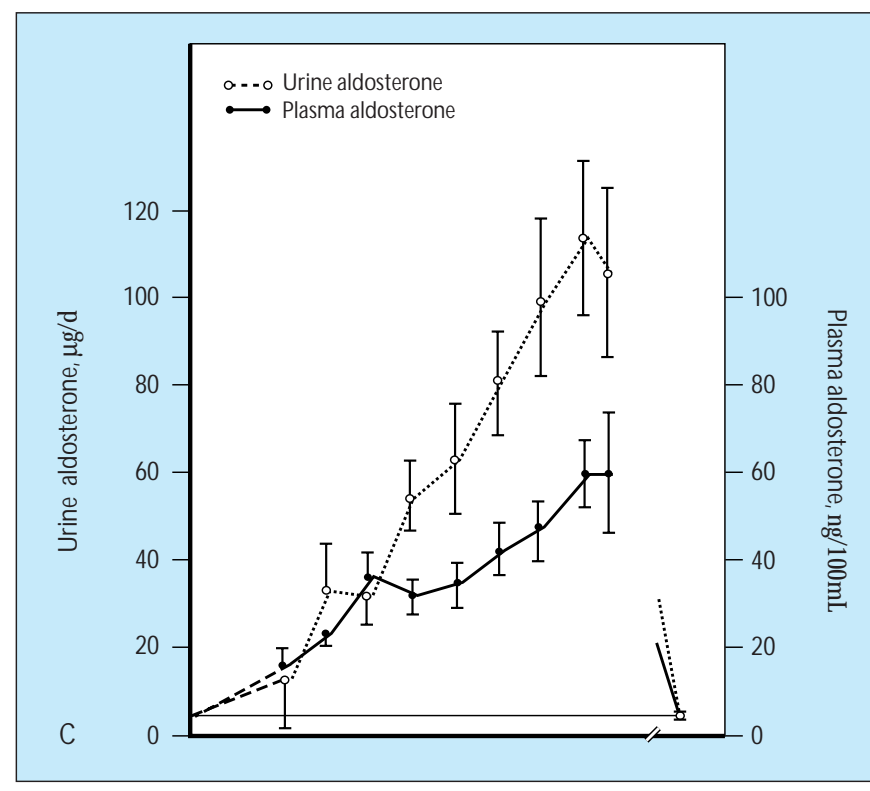

\section{FIGURE 10-4 (Continued)}

C, Changes in renin are associated with commensurate changes in the secretory rate of aldosterone. Although a correlation exists between the increase in renin and that of aldosterone, the latter increases to a greater degree in late pregnancy. This observation suggests that other factors may regulate secretion to a greater degree than does angiotensin II in late gestation. Urinary aldosterone

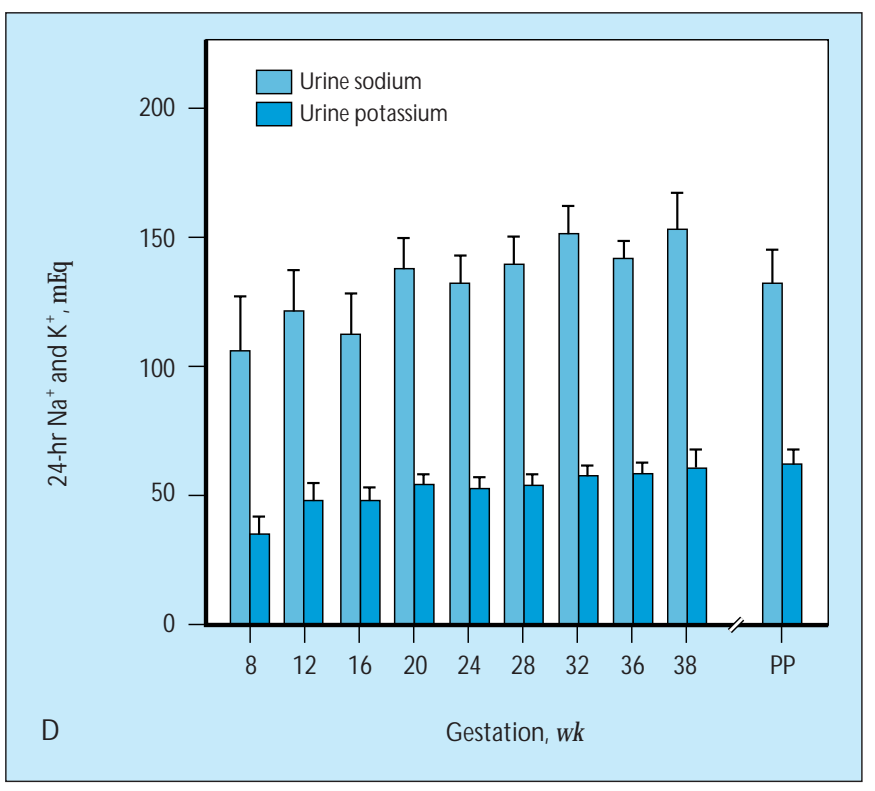

increases in late gestation to a greater degree than does plasma aldosterone, which may reflect an increased production of the 3-oxo conjugate measured in urine. D, Despite the marked increases in aldosterone during pregnancy, 24-hour urinary sodium and potassium excretion remain in the normal range. PP- postpartum. (From Wilson and coworkers [7]; with permission.)

\section{Functional Significance of the Stimulated Renin-Angiotensin System in Pregnancy}

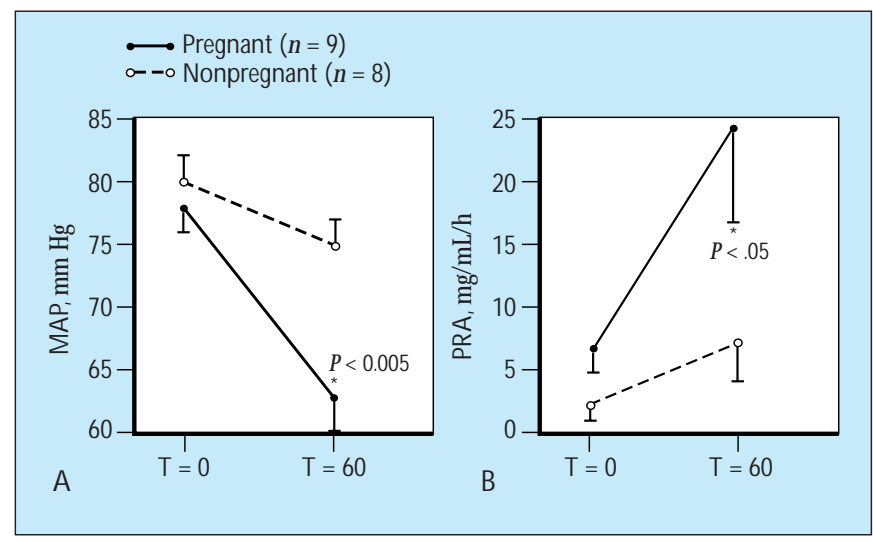

\section{FIGURE 10-5}

Functional significance of the stimulated renin-angiotensin system (RAS) in pregnancy. We determine whether changes in the RAS in pregnancy are primary, and the cause of the increase in plasma volume, or whether these changes are secondary to the vasodilation and changes in blood pressure. To do so, we administered a single dose of captopril to normotensive pregnant women in their first and second trimesters and age-matched normotensive women who were not pregnant. We then measured mean arterial pressure (M AP) and plasma renin activity (PRA) before and 60 minutes after the dose.

A, Despite similar baseline blood pressures, blood pressure decreased more in pregnant women compared with those who were not pregnant in response to captopril. This observation suggests that the RAS plays a greater role in supporting blood pressure in pregnancy. B, Baseline PRA was higher in pregnant women compared with those who were not pregnant, and pregnant women had a greater increase in renin after captopril compared with those who were not pregnant. T-time. (From A ugust and coworkers [8]; with permission.) 


\section{Pregnancy and the Course of Renal Disease}

\section{INTERRELATIONSHIPS BETWEEN PREGNANCY AND RENAL DISEASE}

Impact of pregnancy on renal disease

Hemodynamic changes $\rightarrow$ hyperfiltration

Increased proteinuria

Intercurrent pregnancy-related illness,

eg, preeclampsia

Possibility of permanent loss

of renal function

\section{FIGURE 10-6}

Pregnancy may influence the course of renal disease. Some women with intrinsic renal disease, particularly those with baseline azotemia and hypertension, suffer more rapid deterioration in renal function after gestation. In general, as kidney disease progresses and function deteriorates, the ability to sustain a healthy pregnancy decreases. The presence of hypertension greatly increases the likelihood of renal deterioration [2]. Although hyperfiltration (increased glomerular filtration rate) is a feature of normal pregnancy, increased intraglomerular pressure is not a major concern because the filtration fraction decreases. Possible factors related to the pregnancy-related deterioration in renal function include the gestational increase in proteinuria and intercurrent pregnancy-related illnesses, such as preeclampsia, that might cause irreversible loss of renal function. Women with renal disease are at greater risk for complications related to pregnancy such as preeclampsia, premature delivery, and intrauterine growth retardation.

\section{Diabetes Mellitus and Pregnancy}

\section{RENAL DISEASE CAUSED BY SYSTEMIC ILLNESS}

Gestation in pregnant women with diabetic nephropathy is complicated by the following:

Increased proteinuria, $70 \%$

Decreased creatinine clearance, $40 \%$

Increased blood pressure, $70 \%$

Preeclampsia, 35\%

Fetal developmental problems, $20 \%$

Fetal demise, $6 \%$

\section{FIGURE 10-7}

Diabetes mellitus is a common disorder in pregnant women. Patients with overt nephropathy are likely to develop increased proteinuria and mild but usually reversible deteriorations in renal function during pregnancy. Hypertension is common, and preeclampsia occurs in $35 \%$ of women. (From Reece and coworkers [9]; with permission.) 


\section{Pregnancy and Systemic Lupus Erythematosus}

\begin{tabular}{|c|c|}
\hline \multicolumn{2}{|c|}{ RENAL DISEASE ASSOCIATED WITH SYSTEMIC ILLNESS } \\
\hline Pregnancy and SLE* & Antiphospholipid antibody syndrome in pregnancy \\
\hline Poor outcome is associated with the following: & Increased fetal loss \\
\hline Active disease at conception & Arterial and venous thromboses \\
\hline Disease first appearing during pregnancy & Renal vasculitis, thrombotic microangiopathy \\
\hline Hypertension, azotemia in the first trimester & Preeclampsia \\
\hline $\begin{array}{l}\text { High titers of antiphospholipid antibodies or } \\
\text { lupus anticoagulant }\end{array}$ & Treatment: heparin and aspirin? \\
\hline
\end{tabular}

*Systemic lupus erythematosus (SLE) is unpredictable during pregnancy.

\section{FIGURE 10-8}

Patients with systemic lupus erythematosus (SLE) often are women in their childbearing years. Pregnancies in women with evidence of nephritis are potentially hazardous, particularly if active disease is present at the time of conception or if the disease first develops during pregnancy. When hypertension and azotemia are present at the time of conception the risk of complications increases, as it does with other nephropathies [10-14]. The presence of high titers of antiphospholipid antibodies also is associated with poor pregnancy outcome [15]. The presence of antiphospholipid antibodies or the lupus anticoagulant is associated with increased fetal loss, particularly in the second trimester; increased risk of arterial and venous thrombosis; manifestations of vasculitis such as thrombotic microangiopathy; and an increased risk of preeclampsia. Treatment consists of anticoagulation with heparin and aspirin.

\section{Lupus Versus Preeclampsia}

\begin{tabular}{|c|c|c|}
\hline \multicolumn{3}{|c|}{ LUPUS FLARE-UP VERSUS PREECLAMPSIA } \\
\hline & SLE & PE \\
\hline Proteinuria & + & + \\
\hline Hypertension & + & + \\
\hline Erythrocyte casts & + & - \\
\hline Azotemia & + & + \\
\hline Low C3, C4 & + & - \\
\hline Abnormal liver function test results & - & $+1-$ \\
\hline Low platelet count & + & $+/-$ \\
\hline Low leukocyte count & + & - \\
\hline
\end{tabular}

C-complement; minus sign - absent; plus sign - present; $\mathrm{PE}$ - preeclampsia; SLE- systemic lupus erythematosus.

\section{FIGURE 10-9}

In the second or third trimester of pregnancy a clinical flare-up of lupus may be difficult to distinguish from preeclampsia. Treatment of a lupus flare-up might involve increased immunosuppression, whereas the appropriate treatment of preeclampsia is delivery. Thus, it is important to accurately distinguish these entities. Preeclampsia is rare before 24 weeks' gestation. Erythrocyte casts and hypocomplementemia are more likely to be a manifestation of lupus, whereas abnormal liver function test results are seen in preeclampsia and not usually in lupus. 


\section{Chronic Primary Renal Disease in Pregnancy}

\section{CAUSES OF CHRONIC PRIMARY RENAL DISEASE IN PREGNANCY}

Anatomic, congenital

Glomerulonephritis

Interstitial nephritis

Polycystic kidney disease

\section{FIGURE 10-10}

Primary renal disease in pregnancy that is chronic (ie, preceded pregnancy) may result from any of the causes of renal disease in premenopausal women. O verall, the outcome in pregnancy is favorable when the serum creatinine level is less than $1.5 \mathrm{mg} / \mathrm{dL}$ and blood pressure levels are normal in early pregnancy.

\section{Advanced Renal Disease Caused by Polycystic Kidney Disease}

\section{POLYCYSTIC KIDNEY DISEASE AND PREGNANCY}

Increased incidence of urinary tract infection Maternal hypertension associated with poor outcome Extrarenal complications: subarachnoid hemorrhage, liver cysts

\section{FIGURE 10-11}

Although advanced renal disease caused by polycystic kidney disease (PKD) usually develops after childbearing, women with this condition may have hypertension or mild azotemia. Certain considerations are relevant to pregnancy. Pregnancy is associated with an increased incidence of asymptomatic bacteriuria and urinary infection that may be more severe in women with PKD. The presence of maternal hypertension has been shown to be associated with adverse pregnancy outcomes [16]. Pregnancy has been reported to be associated with increased size and number of liver cysts owing to estrogen stimulation. Women with intracranial aneurysms may be at increased risk of subarachnoid hemorrhage during labor.

\section{Management of Chronic Renal Disease During Pregnancy}

\section{MANAGEMENT OFCHRONIC RENAL DISEASEDURING PREGNANCY}

\section{Preconception counseling}

Multidisciplinary approach

Frequent monitoring of blood pressure (every 1-2 wk) and renal function (every mo)

Balanced diet (moderate sodium, protein)

Maintain blood pressure at 120-140/80-90 mm Hg

Monitor for signs of preeclampsia

\section{FIGURE 10-12}

$M$ anagement of chronic renal disease during pregnancy is best accomplished with a multidisciplinary team of specialists.

Preconception counseling permits the explanation of risks involved with pregnancy. Patients should understand the need for frequent monitoring of blood pressure and renal function. Protein restriction is not advisable during gestation. Salt intake should not be severely restricted. When renal function is impaired, modest salt restriction may help control blood pressure. Blood pressure should be maintained at a level at which the risk of maternal complications owing to elevated blood pressure is low. Patients should be monitored closely for signs of preeclampsia, particularly in the third trimester. 


\section{Renal Disease During Pregnancy}

\section{MOST COMMON CAUSES OF DE NOVO RENAL DISEASE IN PREGNANCY}

\begin{tabular}{ll}
\hline \hline Glomerulonephritis & Interstitial nephritis \\
Lupus nephritis & Obstructive uropathy \\
Acute renal failure & \\
\hline \hline
\end{tabular}

\section{FIGURE 10-13}

Renal disease may develop de novo during pregnancy. The usual causes are new-onset glomerulonephritis or interstitial nephritis, lupus nephritis, or acute renal failure. Rarely, obstructive uropathy develops as a result of stone disease or large myomas that have increased in size during pregnancy.

\section{Investigation of the Cause of Renal Disease During Pregnancy}

\section{RENAL EVALUATION \\ DURING PREGNANCY}

\begin{tabular}{l}
\hline \hline Serology \\
Function \\
Ultrasonography \\
Biopsy: <32 wk \\
Deteriorating function \\
Morbid nephrotic syndrome \\
\hline \hline
\end{tabular}

\section{FIGURE 10-14}

Investigation of the cause of renal disease during pregnancy can be conducted with serologic, functional, and ultrasonographic testing. Renal biopsy is rarely performed during gestation. Renal biopsy usually is reserved for situations in which renal function suddenly deteriorates without apparent cause or when symptomatic nephrotic syndrome occurs, particularly when azotemia is present. Almost no role exists for renal biopsy after gestational week 32 because at this stage the fetus will likely be delivered, independent of biopsy results [17].

\section{New-Onset Azotemia, Proteinuria, and Hypertension Occurring in the Second Half of Pregnancy}

\section{INTRINSIC RENAL DISEASE VERSUS PREECLAMPSIA}

\begin{tabular}{lll}
\hline \hline & Renal disease & Preeclampsia \\
\hline Serum creatinine & $>1.0 \mathrm{mg} / \mathrm{dL}$ & $0.8-1.2 \mathrm{mg} / \mathrm{dL}$ \\
Urinary protein & Variable & $>300 \mathrm{mg} / \mathrm{d}$ \\
Uric acid & Variable & $>5.5 \mathrm{mg} / \mathrm{dL}$ \\
Blood pressure & Variable & $>140 / 90 \mathrm{~mm} \mathrm{Hg}$ \\
Liver function test results & Normal & May be increased \\
Platelet count & Normal & May be decreased \\
Urine analysis & Variable & Protein, with or without \\
& & erythrocytes, leukocytes \\
& & \\
\hline \hline
\end{tabular}

\section{FIGURE 10-15}

$\mathrm{N}$ ew-onset azotemia, proteinuria, and hypertension occurring in the second half of pregnancy should be distinguished from preeclampsia. M ost cases of preeclampsia are associated with only mild azotemia; significant azotemia is more suggestive of renal disease. Azotemia in the absence of proteinuria or hypertension would be unusual in preeclampsia, and thus, would be more suggestive of intrinsic renal disease. Thrombocytopenia, elevated liver function test results, and significant anemia are not typical features of renal disease (except for thrombotic microangiopathic syndromes) and are features of the variant of preeclampsia known as the hemolysis, elevated liver enzymes, and low platelet count (HELLP) syndrome. 


\section{Acute Tubular Necrosis and Pregnancy}

\begin{tabular}{l} 
ACUTE RENAL FAILURE \\
IN PREGNANCY \\
\hline \hline \\
Acute tubular necrosis; hemodynamic factors, toxins, \\
serious infection, and so on \\
Acute interstitial nephritis \\
Acute fatty liver of pregnancy \\
Preeclampsia-HELLP syndrome \\
Microangiopathic syndromes \\
Acute cortical necrosis: obstetric hemorrhage \\
\hline \hline
\end{tabular}

HELLP- hemolysis, elevated liver enzymes, and low platelet count.

\section{FIGURE 10-16}

M ost pregnant women with acute renal failure have acute tubular necrosis secondary to either hemodynamic factors, toxins, or serious infection. O ccasionally, glomerulonephritis or obstructive nephropathy may be seen. A cute cortical necrosis may complicate severe obstetric hemorrhage. A cute renal failure may be a complication of the rare syndrome of acute fatty liver of pregnancy, a disorder that occurs late in gestation characterized by jaundice and severe hepatic dysfunction. This syndrome has features that overlap with the hemolysis, elevated liver enzymes, and low platelet count (H ELLP) syndrome variant of preeclampsia as well as microangiopathic syndromes (eg, hemolytic uremic syndrome and thrombotic thrombocytopenic purpura).

\section{HELLP Syndrome, AFLP, TTP, and HUS}

\section{DIFFERENTIAL DIAGNOSIS OF MICROANGIOPATHIC SYNDROMESDURING PREGNANCY}

\begin{tabular}{|c|c|c|c|c|}
\hline & HELLP & AFLP & TTP & HUS \\
\hline Hypertension & $80 \%$ & $25-50 \%$ & Occasional & Present \\
\hline Renal insufficiency & Mild to moderate & Moderate & Mild to moderate & Severe \\
\hline $\begin{array}{l}\text { Fever, neurologic } \\
\text { symptoms }\end{array}$ & 0 & 0 & ++ & 0 \\
\hline Onset & 3rd trimester & 3rd trimester & Any time & Postpartum \\
\hline Platelet count & Low to very low & Low to very low & Low to very low & Low to very low \\
\hline $\begin{array}{l}\text { Liver function test } \\
\text { results }\end{array}$ & High to very high & $\begin{array}{l}\text { High to extremely } \\
\text { high }\end{array}$ & Usually normal & Usually normal \\
\hline $\begin{array}{l}\text { Partial thromboplastin } \\
\text { time }\end{array}$ & Normal to high & High & Normal & Normal \\
\hline Antithrombin III & Low & Low & Normal & Normal \\
\hline
\end{tabular}

AFLP-acute fatty liver of pregnancy; HELLP - hemolysis, elevated liver enzymes, and low platelet count; HUS- hemolytic uremic syndrome; TTP-thrombotic thrombocytopenic purpura.

Adapted from Saltiel et al. [18].

\section{FIGURE 10-17}

H emolysis, elevated liver enzymes, and low platelet count (HELLP) syndrome; acute fatty liver of pregnancy (AFLP); thrombotic thrombocytopenic purpura (TTP); and hemolytic uremic syndrome (HUS) have similar clinical and laboratory features [18,19]. The subtle differences are summarized. (A dapted from Saltiel and coworkers [18].) 


\section{Fertility in Women in End-Stage Renal Disease}

\begin{tabular}{l} 
DIALYSISAND PREGNANCY \\
\hline \hline Successful outcome, $20-30 \%$ \\
High incidence of prematurity \\
Outcome related to residual maternal renal function \\
Management: \\
Increased hours on dialysis \\
Erythropoietin therapy \\
Blood pressure control \\
Therapy with low doses of heparin \\
Continuous ambulatory peritoneal dialysis versus \\
hemodialysis? \\
\hline \hline
\end{tabular}

\section{FIGURE 10-18}

Because fertility is decreased in end-stage renal disease, pregnancy is uncommon in women on chronic dialysis. When pregnancies occur, however, only about $20 \%$ to $30 \%$ are successful, with the chances of success increasing when residual renal function exists [20]. The overall strategy should be to maintain blood chemistry levels as close as possible to normal by increasing the number of hours of dialysis to 20 or more. Erythropoietin may be used in pregnancy. Blood pressure control is important, and low doses of heparin should be used to prevent bleeding. There are no apparent advantages of chronic ambulatory peritoneal dialysis compared with hemodialysis. The incidence of worsening maternal hypertension and subsequent premature delivery is high.

\section{Fertility and Renal Transplantation}

\section{RENAL TRANSPLANTATION AND PREGNANCY}

Prognosis depends on blood pressure and baseline renal function

( $<1.5-2 \mathrm{mg} / \mathrm{dL} ;$ normal blood pressure)

Controversy over whether pregnancy accelerates graft loss

Patients are advised to wait $2 \mathrm{y}$ after transplantation before pregnancy

\section{Hypertensive Disorders in Pregnancy}

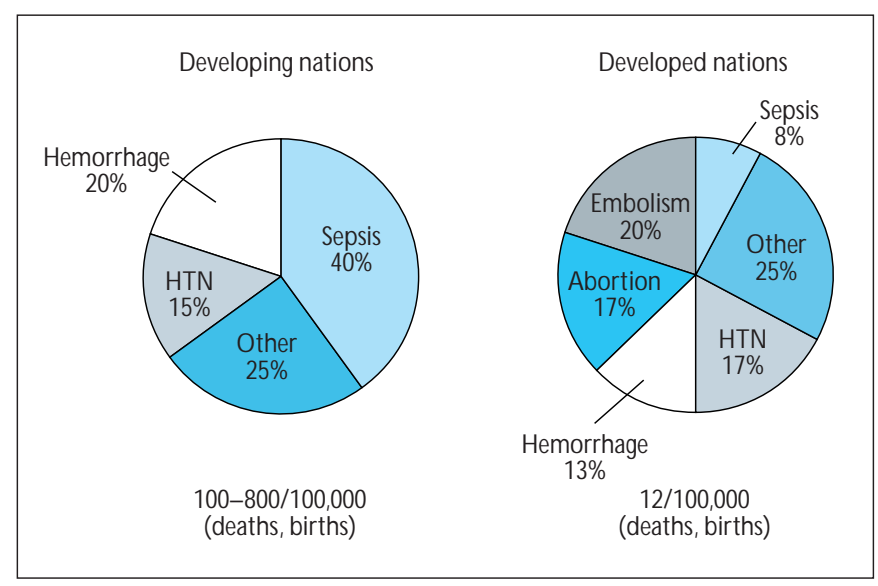

\section{FIGURE 10-19}

Fertility is restored after successful renal transplantation. Pregnancy outcome is improved if renal function is normal and hypertension is absent. It is advisable to wait 2 years after transplantation before pregnancy so that renal function is stable and doses of immunosuppressants are lowest [21]. Cyclosporine, prednisone, and azathioprine are safe during pregnancy and are not associated with fetal abnormalities. Limited experience exists with mycophenolate mofetil during pregnancy.

\section{FIGURE 10-20}

M ortality and hypertension. Worldwide, hypertensive disorders are a major cause of maternal mortality, accounting for almost $20 \%$ of maternal deaths. M ost deaths occur in women with eclampsia and severe hypertension (HTN) and are due to intracerebral hemorrhage [22]. 


\section{FETAL CONSEQUENCES OF MATERNAL HYPERTENSION DURING PREGNANCY}

\author{
3- to 6-fold increase in stillbirths \\ 5- to 15-fold increase in intrauterine growth restriction \\ Premature delivery \\ Long-term developmental and neurologic problems
}

\section{FIGURE 10-21}

$\mathrm{H}$ ypertensive disorders in pregnancy are associated with increased incidences of stillbirth, fetal growth restriction, premature delivery, and long-term developmental problems secondary to prematurity. These complications are more frequent when hypertension is due to preeclampsia.

\section{CLINICAL FEATURES OF CHRONIC HYPERTENSION IN PREGNANCY}

Women are older, more likely to be multiparous Hypertension: present before 20 wk, or documented previous pregnancy Blood pressure may be significantly lower or normal in mid pregnancy Risk of superimposed preeclampsia of $15-30 \%$

\section{CLASSIFICATION OF HYPERTENSIVE DISORDERS IN PREGNANCY}

\section{Preeclampsia, eclampsia \\ Chronic hypertension \\ Chronic hypertension with superimposed preeclampsia \\ Transient hypertension}

\section{FIGURE 10-22}

Several classification systems exist for hypertensive disorders of pregnancy. The one used most commonly in the United States is that proposed in 1972 by the A merican College of $\mathrm{O}$ bstetricians and Gynecologists and endorsed by the $\mathrm{N}$ ational $\mathrm{H}$ igh Blood Pressure Education Program. The distinction is made between the pregnancy-specific hypertensive disorder (preeclampsia, and the convulsive form, eclampsia) and chronic hypertension that precedes pregnancy, which usually is due to essential hypertension. Women with chronic hypertension are at greater risk for preeclampsia (20-25\%). Transient hypertension refers to late pregnancy elevations in blood pressure, without any of the laboratory or clinical features of preeclampsia. This disorder may recur with each pregnancy (in contrast to preeclampsia, which usually is a disease of first pregnancy) and usually indicates a genetic predisposition to essential hypertension.

\section{CLINICAL FEATURES OF PREECLAM PSIA}

\begin{tabular}{l}
\hline \hline Historical: \\
Nulliparity \\
Multiple gestations \\
Family history \\
Preexisting renal or vascular decrease \\
Hypertension: \\
$140 / 90 \mathrm{~mm}$ Hg after 20 wk or \\
$30 \mathrm{~mm}$ Hg increase in systolic pressure or \\
$15 \mathrm{~mm}$ Hg increase in diastolic pressure \\
Sudden appearance of edema, \\
especially in hands and face \\
Rapid weight gain \\
Headache, visual disturbances, \\
abdominal or chest pain \\
\hline \hline
\end{tabular}

\section{FIGURE 10-23}

The diagnosis of preeclampsia is strengthened when one or more of the risk factors are present. $\mathrm{H}$ ypertension develops after 20 weeks, with normal blood pressures in the first half of pregnancy. Although edema is a feature of many normal pregnancies, its sudden appearance in the face and hands in association with a rapid weight gain, is suggestive of preeclampsia. Headache, visual disturbances, and abdominal or chest pain are signs of impending eclampsia.

\section{FIGURE 10-24}

Women with chronic hypertension are usually older and may be multiparous. Although hypertension often is detectable before 20 weeks, in some women the pregnancy-mediated vasodilation is sufficient to normalize blood pressure so that women with stage 1 or 2 hypertension may have normal blood pressures by the time of their first antepartum visit. The risk of preeclampsia is substantially increased in women with chronic hypertension. 


\section{LABORATORY ABNORMALITIES IN PREECLAMPSIA AND CHRONIC HYPERTENSION}

\begin{tabular}{|c|c|c|}
\hline & Chronic hypertension & Preeclampsia \\
\hline \multicolumn{3}{|l|}{ Renal: } \\
\hline Creatinine & Normal & $\begin{array}{l}\text { Increased; increased } \\
\text { blood urea nitrogen, } \\
\text { creatinine }\end{array}$ \\
\hline Uric acid & Normal & Increased (>5.5 mg/dL) \\
\hline Urinary protein & $<300 \mathrm{mg} / \mathrm{d}$ & $>300 \mathrm{mg} / \mathrm{d}$ \\
\hline Urinary calcium & $>200 \mathrm{mg} / \mathrm{d}$ & $<150 \mathrm{mg} / \mathrm{d}$ \\
\hline \multicolumn{3}{|l|}{ Heme: } \\
\hline Hematocrit & Normal & Increased (>38\%) \\
\hline Platelets & Normal & Decreased \\
\hline \multicolumn{3}{|l|}{ Liver function tests: } \\
\hline Aspartate aminotransferase & Normal & Increased \\
\hline Alanine aminotransferase & Normal & Increased \\
\hline Albumin & Normal & Decreased \\
\hline
\end{tabular}

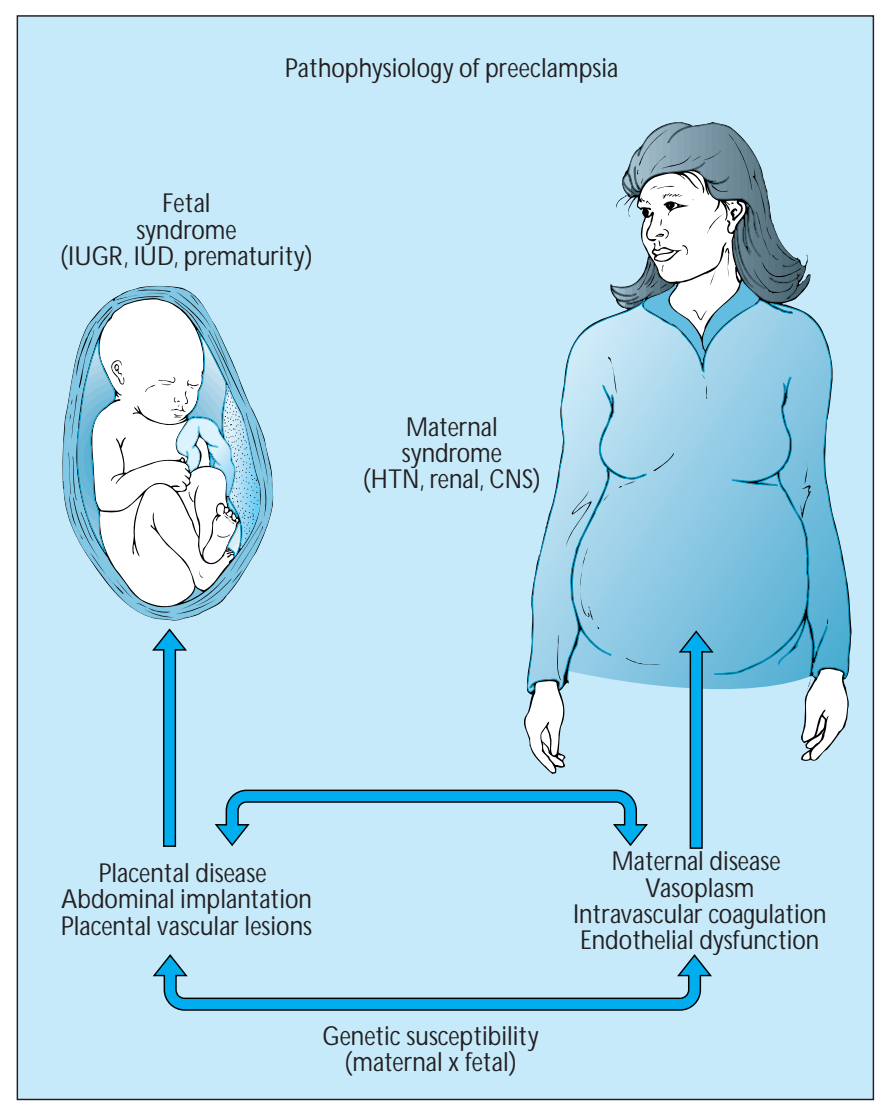

\section{FIGURE 10-25}

Laboratory tests are helpful in making the diagnosis of preeclampsia. In addition to proteinuria, which may occur late in the course of the disease, hyperuricemia, mild azotemia, hemoconcentration, and hypocalciuria are observed commonly. Some women with preeclampsia may develop a microangiopathic syndrome with hemolysis, elevated liver enzymes, and low platelet counts (HELLP). The presence of the HELLP syndrome usually reflects severe disease and is considered an indication for delivery. Women with uncomplicated chronic hypertension have normal laboratory test results unless superimposed preeclampsia or underlying renal disease exists.

\section{FIGURE 10-26}

Preeclampsia is a syndrome with both maternal and fetal manifestations. Current evidence suggests that an underlying genetic predisposition leads to abnormalities in placental adaptation to the maternal spiral arteries that supply blood to the developing fetoplacental unit. These abnormalities in the maternal spiral arteries lead to inadequate perfusion of the placenta and may be the earliest changes responsible for the maternal disease. The maternal disease is characterized by widespread vascular endothelial cell dysfunction, resulting in vasospasm and intravascular coagulation and, ultimately, in hypertension (H TN ), renal, hepatic, and central nervous system (CN S) abnormalities. The fetal syndrome is a consequence of inadequate placental circulation and is characterized by growth restriction and, rarely, demise. Premature delivery may occur in an attempt to ameliorate the maternal condition. IUDintrauterine death; IUGR - intrauterine growth retardation. 


\section{GENETICS OF PREECLAMPSIA}

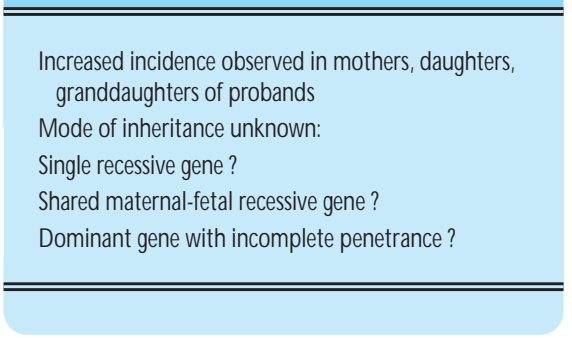

\section{FIGURE 10-27}

A positive family history is a risk factor for preeclampsia, and the incidence is approximately 4 times greater in first-degree relatives of index cases [23]. Cooper and coworkers [24] also noted an increased incidence in relatives by marriage (eg, daughter-in-laws), and 10 instances in which the disease occurred in one but not the other monozygotic twin. These data raise the possibility of paternal or fetal genetic influence [24]. The mode of inheritance of preeclampsia is not known. Several possibilities have been suggested, including a recessive gene with the possibility of a maternal-fetal genotype-by-genotype interaction or a dominant maternal gene with incomplete penetrance.

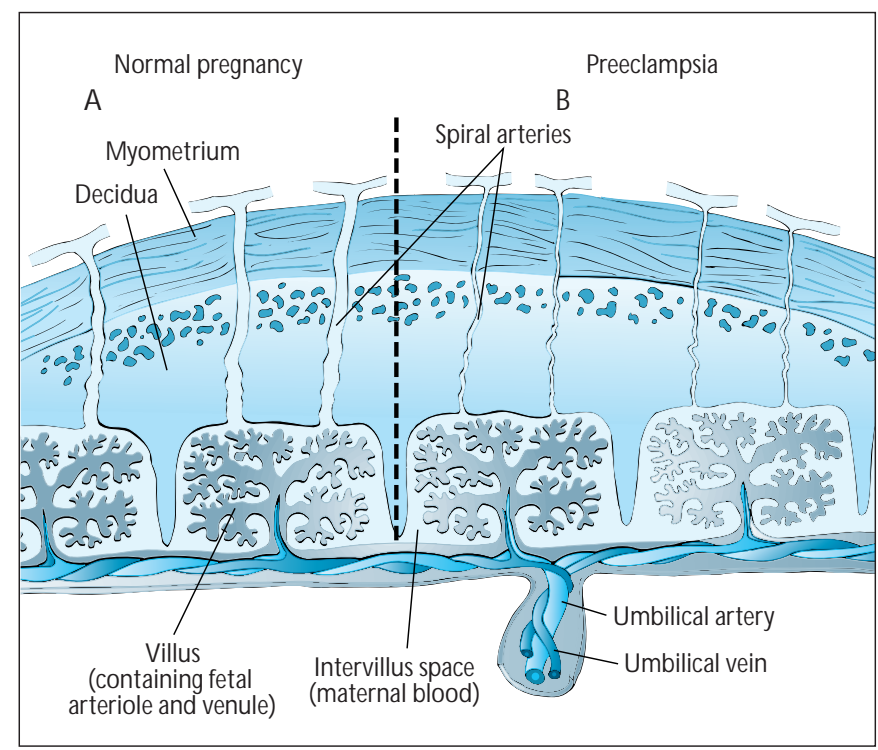

\section{FIGURE 10-28}

Uteroplacental circulation in normal pregnancy and preeclampsia. A, N ormal placentation involves the transformation of the branches of the maternal uterine arteries-the spiral arteries-from thickwalled muscular arteries into saclike flaccid vessels that permit delivery of greater volumes of blood to the uteroplacental unit. B, Evidence exits that in women with preeclampsia this process is incomplete, resulting in relatively narrowed spiral arteries and decreased perfusion of the placenta [25].

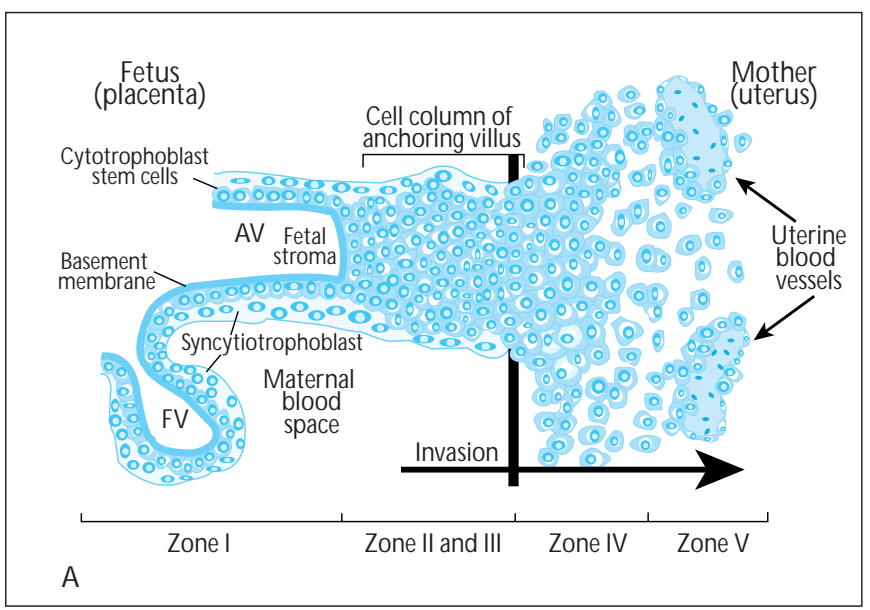

\section{FIGURE 10-29}

Transformation of the spiral arteries. A, The process by which the maternal spiral arteries are transformed into dilated vessels in pregnancy is believed to involve invasion of the spiral arterial walls by endovascular trophoblastic cells. These cells migrate in retrograde fashion, involving first the decidual and then the myometrial segments of the arteries and then causing considerable disruption at all layers of the vessel wall. The mechanisms involved in this complex process are only beginning to be elucidated. These mechanisms involve alterations in the adhesion molecules of the invading trophoblast cells, such that they acquire an invasive phenotype and mimic vascular endothelial cells [26].

(Continued on next page) 

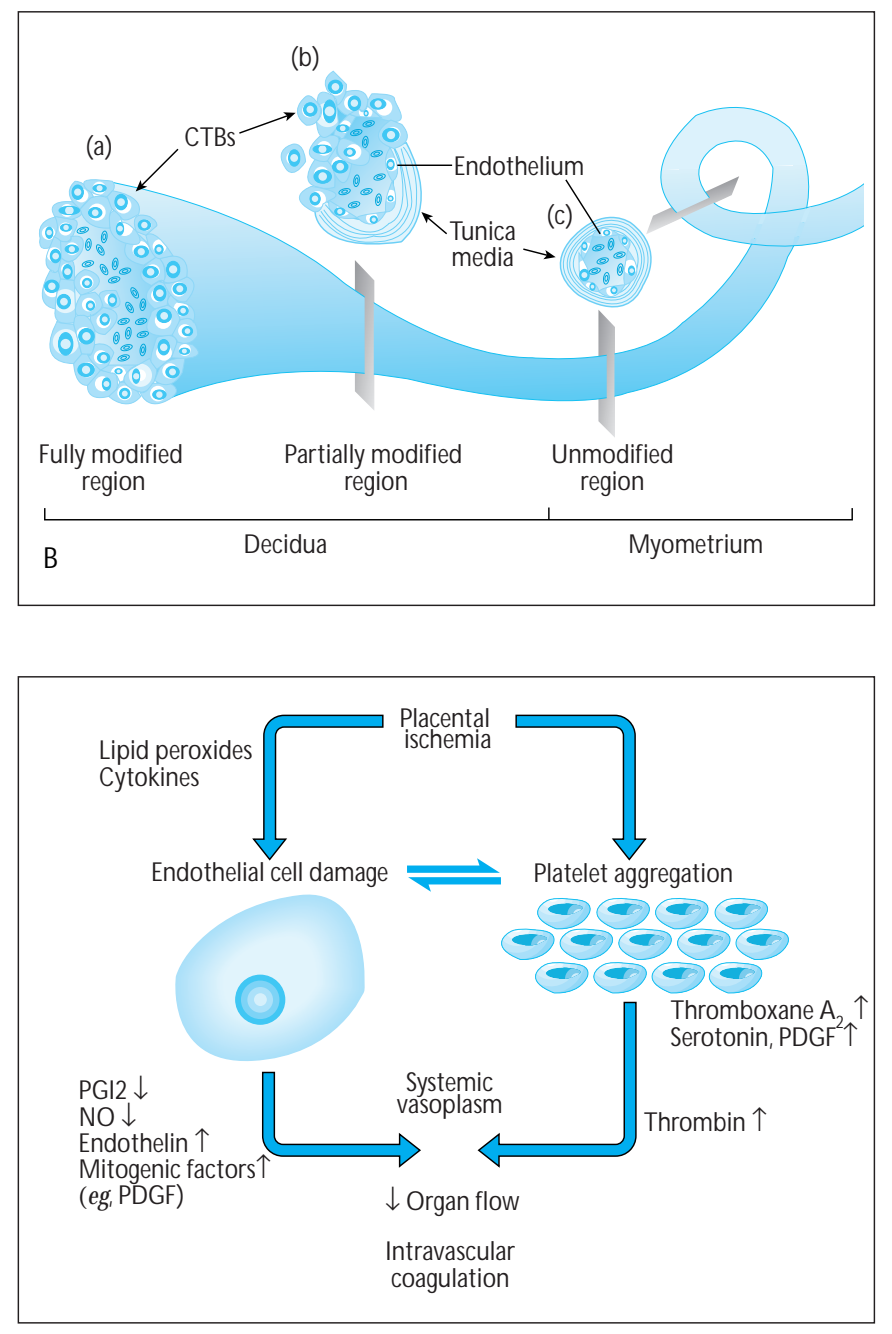

\section{FIGURE 10-29 (Continued)}

B, In women destined to develop preeclampsia, trophoblastic invasion of the spiral arteries is incomplete; it may occur in the decidual but not the myometrial segments of the artery, and in some vessels the process does not occur at all. The arteries, therefore, remain thick-walled and muscular, the diameters in the myometrial segments being half those measured during normal pregnancy. Recently, it has been reported that in preeclampsia the invading cytotrophoblasts fail to properly express adhesion receptors necessary for normal remodeling of the maternal spiral arteries [27]. This failure of cytotrophoblast invasion of the spiral arteries is considered to be the morphologic basis for decreased placental perfusion in preeclampsia. (a)-fully modified regions. (b)- partially modified vessel segments. (c)- unmodified vessel segments in the myometrium. AV-anchoring villus; CTBs-cytotrophoblast cells; FV-floating villi. (From Zhou and coworkers [27]; with permission.)

\section{FIGURE 10-30}

Pathophysiology of preeclampsia. A major unresolved issue in the pathophysiology of preeclampsia is the mechanism whereby abnormalities in placental modulation of the maternal circulation lead to maternal systemic disease. The current schema, which is a hypothesis, depicts a scenario whereby placental ischemia leads to the release of substances that might be toxic to maternal endothelial cells. The resulting endothelial cell dysfunction also results in increased platelet aggregation. These events lead to the widespread systemic vasospasm, intravascular coagulation and decreased organ flow that are characteristic of preeclampsia. $\mathrm{NO}$ - nitric oxide; PD GF- platelet-derived grow th factor; PG I2- prostacyclin 2. 


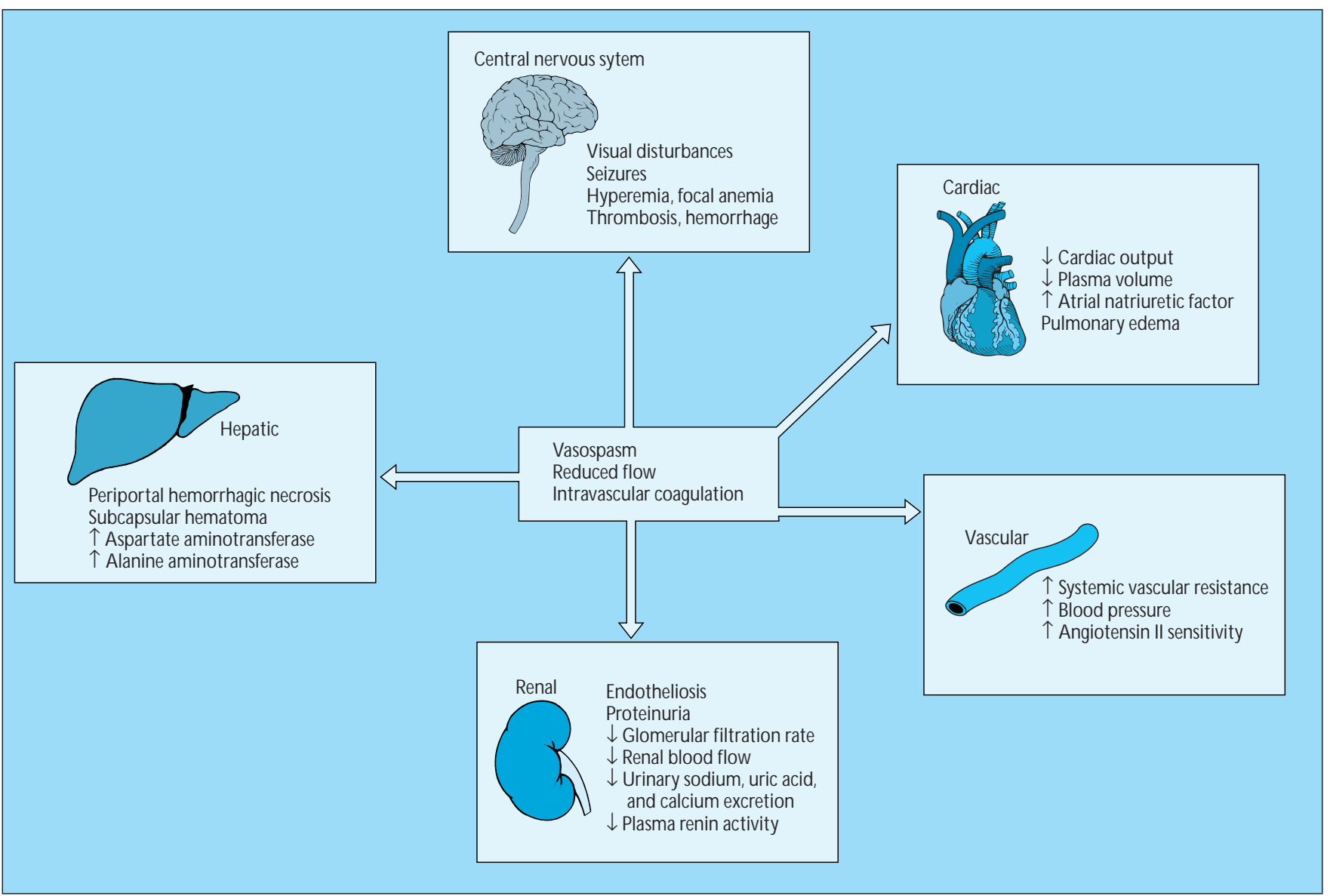

\section{FIGURE 10-31}

$M$ aternal manifestations of preeclampsia. Preeclampsia is a multisystem maternal disorder, with dramatic alterations in heart, kidney, circulation, liver, and brain. Interestingly, all of these abnormalities resolve within a few weeks of delivery. 


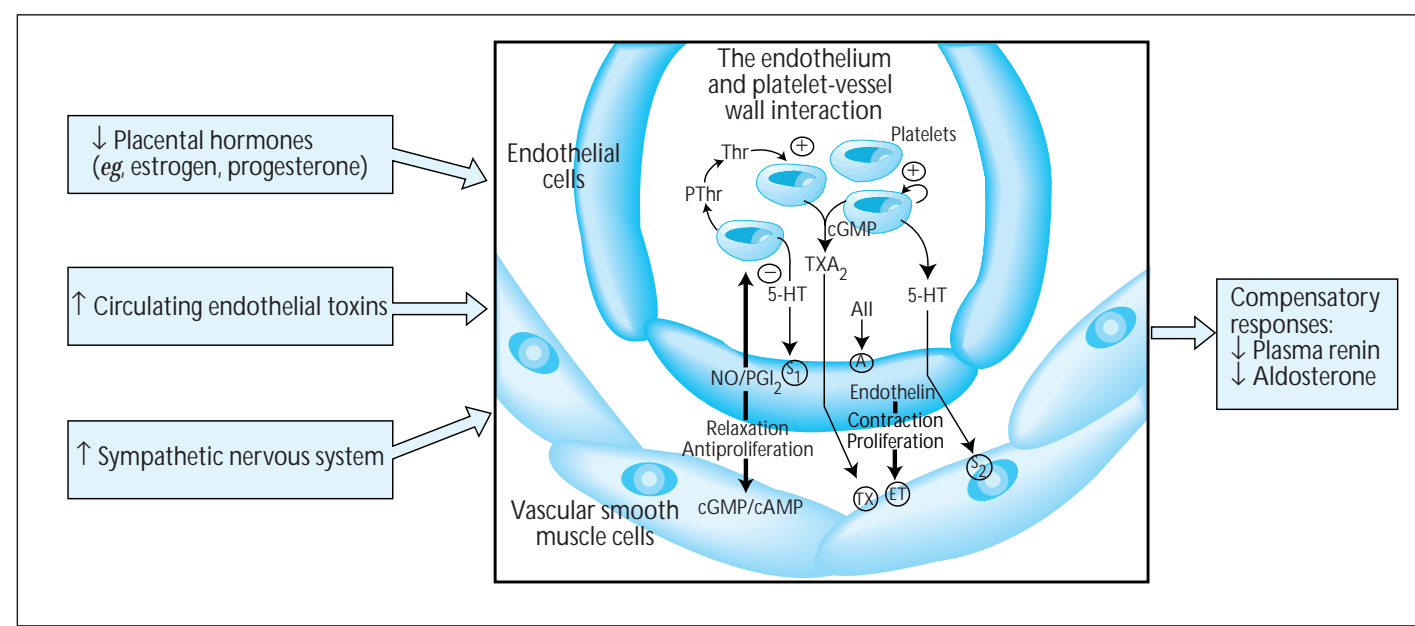

\section{FIGURE 10-32}

$\mathrm{H}$ ypertension in preeclampsia. Although the mechanism of the increased blood pressure in preeclampsia is not established, evidence suggests it may involve multiple processes. A possible scenario involves the following: decreased placental production of estrogen and progesterone, both of which have hemodynamic effects; increased circulating endothelial toxins, possibly released from a poorly perfused placenta; and increased activity of the sympathetic nervous system. These processes may then result in alterations in platelet- vascular endothelial cell function, with decrease in vasodilators such as nitric oxide and prostacyclin and increased production of vasoconstrictors such as endothelin (ET). Compensatory suppression of the reninangiotensin system occurs, suggesting that excess angiotensin II (AII) does not play a major role in preeclamptic hypertension (HT). Finally, sodium retention owing to renal vasoconstriction may further increase blood pressure. CAM P-cyclic adenosine monophosphate; cGM Pcyclic guanosine monophosphate; $5-\mathrm{HT}-$ serotonin; PThrparathyroid hormone; $\mathrm{S}_{2}$ - serotonergic receptors; Thr - thombin TX thromboxane; $\mathrm{TXA}_{2}$ thromboxane $\mathrm{A}_{2}$. (Adapted from Lüscher and Dubey [28]; with permission.)

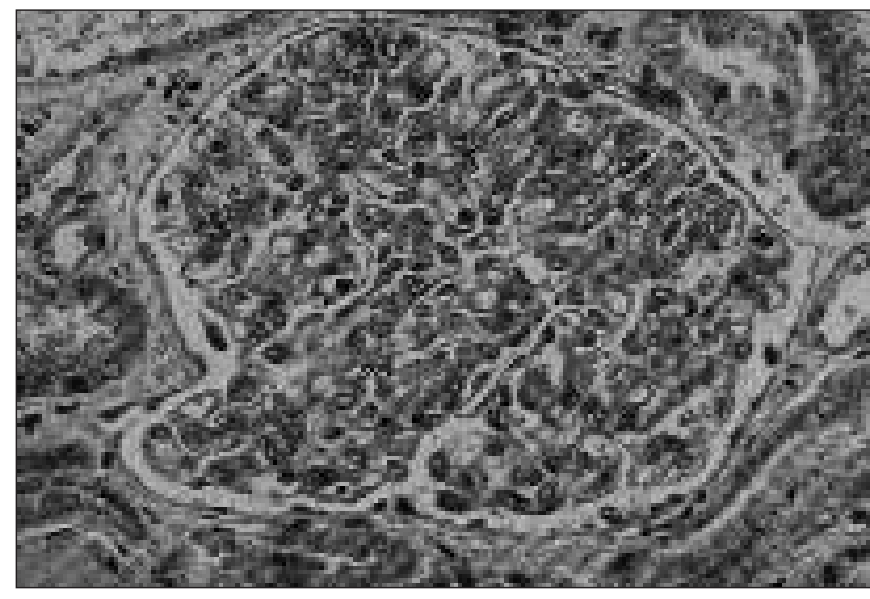

\section{FIGURE 10-33}

Light microscopy of the renal lesion of preeclampsia: glomerular endotheliosis. On light microscopy, the glomeruli from preeclamptic women are characterized by swelling of the endothelial and mesangial cells. This swelling results in obliteration of the capillary lumina, giving the appearance of a bloodless glomerulus. O n occasion, the mesangium, severely affected, may expand. Thrombosis and fibrinlike material and foam cells may be present, and epithelial crescents have been described in rare instances [2].

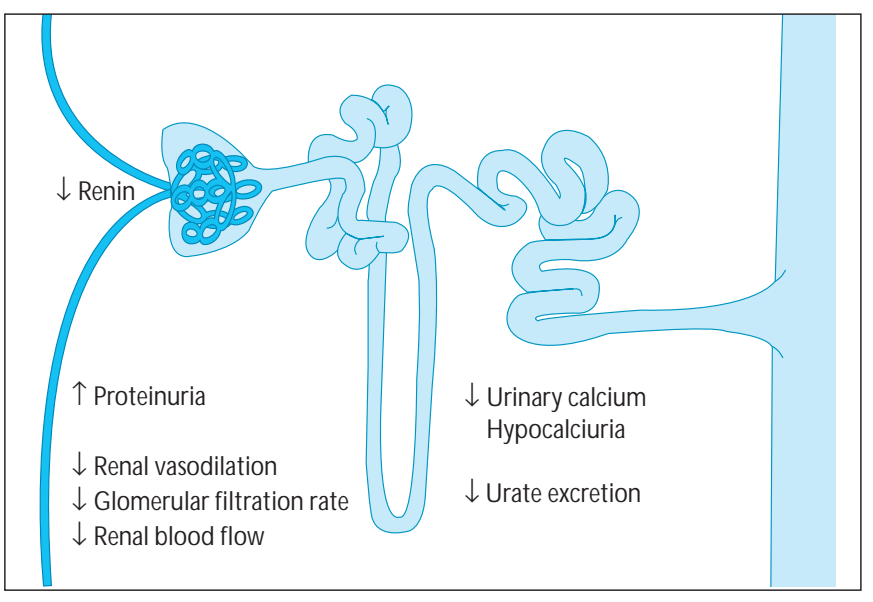

\section{FIGURE 10-34}

Functional renal alterations in preeclampsia. The functional consequences of glomerular endotheliosis and of the hormonal alterations in preeclampsia are summarized in this schematic diagram of the nephron in preeclampsia. Suppression of the reninangiotensin system occurs, probably in response to vasoconstriction and elevated blood pressure. The glomerular lesion leads to proteinuria, which may be heavy. Renal hemodynamic changes include modest decreases in the glomerular filtration rate (GFR) and renal blood flow (RBF). Decreased sodium and uric acid excretion may be caused by increased proximal tubular reabsorption. The mechanism for the marked hypocalciuria is not known. 


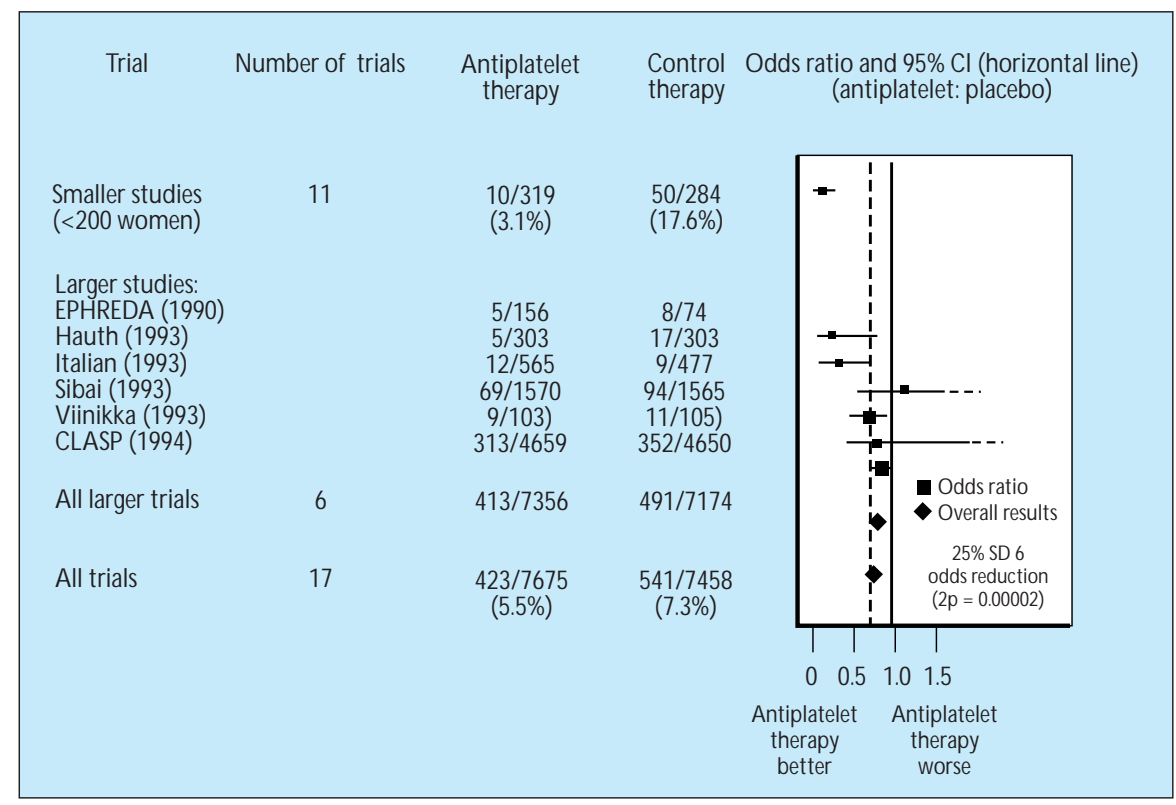

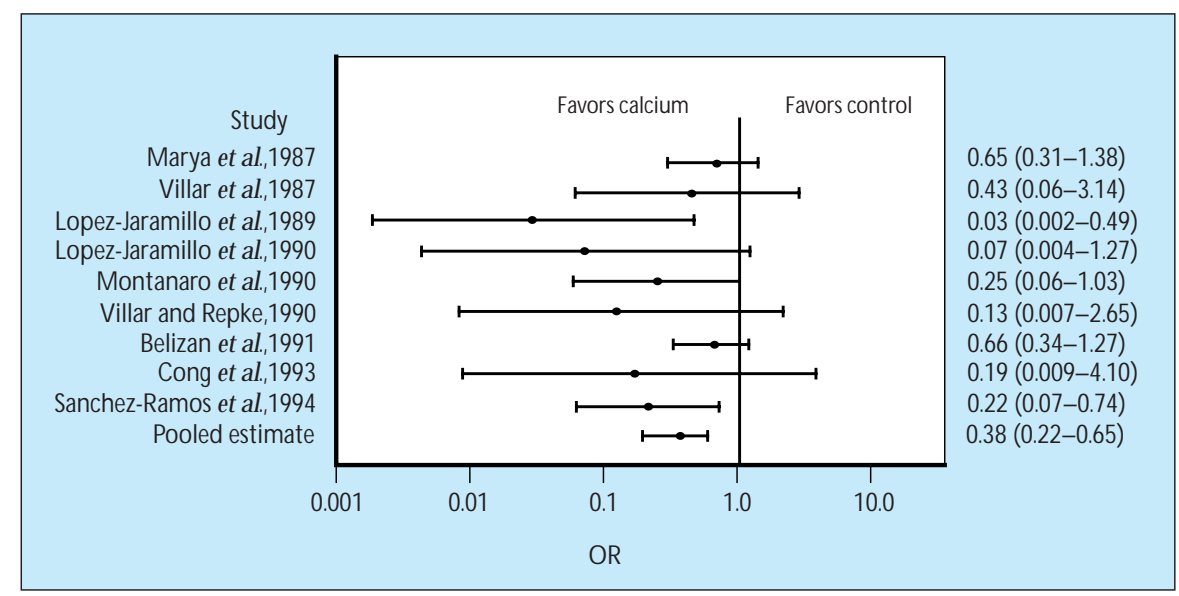

\section{FIGURE 10-35}

Prevention of preeclampsia with low-dose aspirin. Investigators have sought methods to prevent preeclampsia (eg, salt restriction, prophylactic diuretics, and high-protein diets). O ne approach that has been extensively investigated in the last 10 years is therapy with low-dose aspirin. It was hypothesized that such therapy reversed the imbalance between prostacyclin and thromboxane that may be responsible for some of the manifestations of the disease. Several large trials now have been completed, and most have had negative results. Shown here is an overview of the effects of aspirin on proteinuric preeclampsia reported from all trials of antiplatelet therapy (through 1994) as analyzed by the Collaborative Low-dose Aspirin in Pregnancy (CLASP) Collaborative Group [28]. O dds ratios (area proportional to amount of information contributed) and 99\% confidence interval $(\mathrm{Cl})$ are plotted for various trials. A black square to the left of the solid vertical line suggests a benefit (however, this indication is significant at $2 p>0.01$ only if the entire $\mathrm{Cl}$ is to the left of solid vertical line). (From CLASP Collaborative Group [29]; with permission.)

\section{FIGURE 10-36}

Prevention of preeclampsia using calcium supplementation. Another preventive strategy that has been extensively investigated, with conflicting outcomes, is calcium supplementation. The rationale for this approach is based on the observations that low dietary calcium intake may increase the risk for preeclampsia, and that preeclampsia is characterized by abnormalities in calcium metabolism that suggest a calcium deficit, eg, decreased vitamin D and hypocalciuria [31]. A recent meta-analysis of 14 trials of calcium supplementation in pregnancy concluded that calcium supplementation during pregnancy leads to reductions in blood pressure and a lower incidence of preeclampsia. In contrast, a large randomized trial of calcium supplementation in 4589 low-risk women failed to demonstrate a benefit of calcium therapy [31]. CI-confidence interval; OR-odds ratio. (From Bucher and coworkers [30]; with permission.) 


\section{TREATMENT OF PREECLAMPSIA}

Close monitoring of maternal and fetal conditions Hospitalization in most cases Lower blood pressure for maternal safety Seizure prophylaxis with magnesium sulfate Timely delivery

\section{ANTIHYPERTENSIVE THERAPY IN PREECLAMPSIA}

Decreased uteroplacental blood flow and placental ischemia are central to the pathogenesis of preeclampsia.

Lowering blood pressure does not prevent or cure preeclampsia and does not benefit the fetus unless delivery can be safely postponed.

Lowering blood pressure is appropriate for maternal safety: maintain blood pressure at 130-150/85- $100 \mathrm{~mm} \mathrm{Hg}$.

\section{FIGURE 10-37}

Treatment of preeclampsia requires close monitoring of both the maternal and fetal condition to maximize chances of avoiding catastrophes such as seizures, renal failure, and fetal demise. Close surveillance is best accomplished in the hospital in all but the mildest cases. $M$ aternal hypertension should be treated to avoid cerebrovascular and cardiovascular complications. $M$ agnesium sulfate is the treatment of choice for seizure prophylaxis and usually is instituted immediately after delivery. When the fetus is mature, delivery is indicated in all cases. When the fetus is immature, the decision to deliver is made after carefully assessing both the maternal and fetal condition. When maternal health is in jeopardy, delivery is necessary, even with a premature fetus.

\section{FIGURE 10-38}

Some controversy exists regarding when to institute antihypertensive therapy in women with preeclampsia. The basis for this controversy is that decreased uteroplacental perfusion is believed to be important in the pathophysiology of this disorder, and concern exists that lowering maternal blood pressure may compromise uteroplacental blood flow and lead to fetal distress. Furthermore, lowering maternal blood pressure does not cure preeclampsia. Thus, antihypertensive therapy is instituted when the blood pressure reaches a level at which the physician considers the maternal condition to be in danger from hypertension. For most physicians, this treatment threshold is at approximately $150 / 100 \mathrm{~mm} \mathrm{H} \mathrm{g}$. Aggressive lowering of blood pressure is not advisable.

\section{ANTIHYPERTENSIVE THERAPY IN PREECLAMPSIA}

\begin{tabular}{ll}
\hline \hline Imminent delivery & Delivery postponed \\
\hline Hydralazine (intravenous, intramuscular) & Methyldopa \\
Labetalol (intravenous) & Labetalol, other $\beta$ blockers \\
Calcium channel blockers & Calcium channel blockers \\
Diazoxide (intravenous) & Hydralazine \\
& $\alpha$ blockers \\
& Clonidine \\
\hline \hline
\end{tabular}

\section{FIGURE 10-39}

When blood pressure increases acutely and delivery is likely within the next 24 hours, use of a parenteral antihypertensive agent is preferable. Intravenous hydralazine or labetalol are acceptable agents for pregnant women, and both have been used successfully in preeclampsia. Calcium channel blockers should be used with caution because they may act synergistically with magnesium sulfate, resulting in precipitous decreases in blood pressure. Rarely, agents such as diazoxide may be needed; how ever, when hypertension is severe, maternal safety takes priority over pregnancy status. When delivery can be postponed safely for several days, an oral agent is indicated. M ethyldopa is one of the safest drugs in pregnancy and has been used extensively with excellent maternal and fetal outcome. Labetalol and other $\beta$ blockers have been used successfully in preeclampsia. Calcium channel blockers also may be used as either second- or third-line agents. O ral hydralazine is safe in pregnancy. Limited experience exists with $\alpha$ blockers or clonidine, although anecdotal reports suggest these agents are safe. 


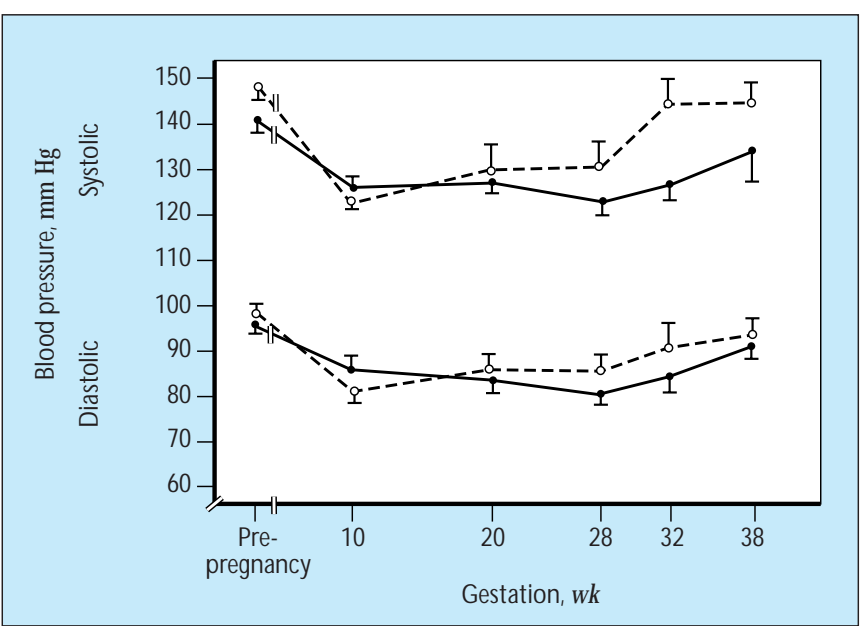

\section{FIGURE 10-40}

Blood pressure changes during pregnancy in women with chronic hypertension. Women with preexisting or chronic hypertension during pregnancy have a favorable prognosis, unless preeclampsia develops. The risk of superimposed preeclampsia is about $25 \%$. Women with this complication are at greater risk for fetal complications during pregnancy, including premature delivery, growth restriction, and perinatal mortality.

Women with chronic hypertension experience a decrease in blood pressure during pregnancy that may permit withdrawal of some or all antihypertensive medication. In those women with uncomplicated chronic hypertension (solid line), blood pressure decreases in the first trimester, then may decrease even further in the second trimester. A $n$ increase in both systolic and diastolic blood pressure may occur during the third trimester to levels at prepregnancy or early first trimester. In those women who develop superimposed preeclampsia (broken lines), blood pressure often decreases in the first trimester. There is often a failure to decrease further in the second trimester, however, and blood pressures may actually begin to increase slightly. Blood pressure then increases significantly when preeclampsia develops [33].

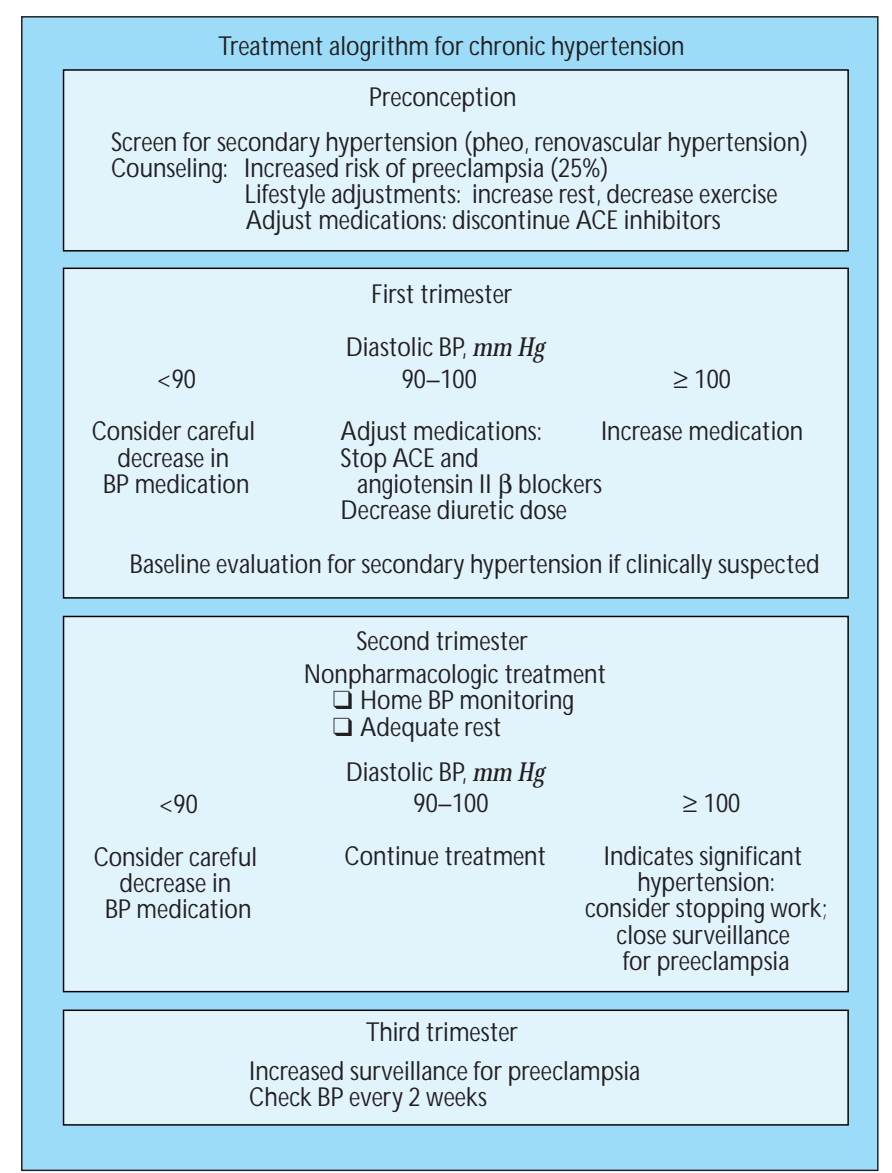

\section{FIGURE 10-41}

Treatment algorithm for chronic hypertension. Ideally, patients with chronic hypertension should be evaluated before pregnancy so that secondary hypertension can be diagnosed and treated appropriately. Women can be counseled regarding the need for possible life-style adjustments, and medications can be adjusted. Blood pressure (BP) medications may require adjustment, depending on the magnitude of the pregnancy-related changes in blood pressure. In the latter half of pregnancy, close surveillance for early signs of preeclampsia increases the likelihood the condition will be diagnosed before it progresses to a severe stage.

\section{ANTIHYPERTENSIVE THERAPY FOR CHRONIC HYPERTENSION DURING PREGNANCY}

Methyldopa

$\beta$ blockers (labetalol)

Calcium channel blockers

Hydralazine

Diuretics

\section{FIGURE 10-42}

The overall treatment goals of chronic hypertension in pregnancy are to ensure a successful full-term delivery of a healthy infant without jeopardizing maternal well-being. The level of blood pressure control that is tolerated in pregnancy may be higher, because the risk of exposure of the fetus to additional antihypertensive agents might outweigh the benefits to the mother (for the duration of pregnancy) of having a normal blood pressure. $\mathrm{M}$ ost antihypertensive agents have been evaluated only sporadically during gestation, and careful follow-up of children exposed in utero to many of the agents is lacking. The only antihypertensive agent for which such follow-up exists is methyldopa. Because no adverse effects have been documented in offspring of exposed mothers, methyldopa is considered to be one of the safest drugs during pregnancy. $\beta$ blockers and calcium channel blockers are acceptable second- and third-line agents. Diuretics can be used at low doses, particularly in salt-sensitive hypertensive patients on chronic diuretic therapy. Angiotensin-converting enzyme inhibitors are contraindicated in pregnancy because they adversely affect fetal renal function. A ngiotensin II receptor antagonists are presumed to have similar effects but have not been evaluated in human pregnancy. 
1. Baylis C: Glomerular filtration and volume regulation in gravid animal models. Clin O bstet G ynaecol 1987, 1:789.

2. Lindheimer M D, Katz AI: The kidney and hypertension in pregnancy. In The Kidney, edn 4. Edited by Brenner BM , Rector FC. Philadelphia: WB Saunders C0; 1991:1551-1595.

3. Davison JM, Shiells EA, Philips PR, Lindheimer M D: Serial evaluation of vasopressin release and thirst in human pregnancy: role of chorionic gonadotropin in the osmoregulatory changes of gestation. J Clin Invest 1988, 81:798.

4. Lindheimer M D, Richardson DA, Ehrlich EN, Katz Al: Potassium homeostasis in pregnancy. J Reprod M ed 1987, 32:517.

5. Brown M A, Sinosich MJ, Saunders DM , Gallery EDM : Potassium regulation and progesterone-aldosterone interrelationships in human pregnancy. A prospective study. Am J O bstet G ynecol 1986, 155:349.

6. Lim VS, Katz AI, Lindheimer M D: Acid-base regulation in pregnancy. Am J Physiol 1976, 231:1764.

7. Wilson M, M organti AA, Zervoudakis I, et al.: Blood pressure, the reninaldosterone system and sex steroids throughout normal pregnancy. Am J Med 1980, 68:97.

8. August P, M ueller FB, Sealey JE, Edersheim TG: Role of reninangiotensin system in blood pressure regulation in pregnancy. L ancet 1995, 345:896-897.

9. Diabetic nephropathy. Pregnancy performance and fetal-maternal outcome. Am J O bstet G ynecol 1988, 159:56.

10. H ayslett JP, Lynn RI: Effect of pregnancy in patients with lupus nephropathy. Kidney Int 18:207, 1980.

11. Houser M T, Fish AJ, Tagatz GE, et al.: Pregnancy and systemic lupus erythematosus. Am J O bstet Gynecol 1980, 138:409.

12. Fine $L G$, Barnett $E V, D$ anovitch $G M$, et al.: Systemic lupus erythematosus in pregnancy. Ann Intern M ed 1981, 94:667.

13. Imbasciati $E$, Surian $M$, Bottino $S$, et al: Lupus nephropathy and pregnancy. A study of 26 pregnancies in patients with systemic lupus erythematosus and nephritis. N ephron 1984, 36:46.

14. Jungers $P$, Dougodos $M$, Pelissier C, et al.: Lupus nephropathy and pregnancy. Report of 104 cases in 36 patients. Arch Intern M ed 1982, $142: 771$.

15. Lockshin M D, Druzin M C, Goel S, et al.: Antibody to cardiolipin as a predictor of fetal distress on death in pregnant patients with systemic lupus erythematosus. N Engl J M ed 1985, 313:152.

16. Chapman AB, Johnson AM, Gabow PA: Pregnancy outcome and its relationship to progression of renal failure in autosomal dominant polycystic kidney disease. J Am Soc N ephrol 1994, 5:1178-1185.

17: Lindheimer M D, Davison JM . Renal biopsy during pregnancy: "To b... or not to b..." Br J O bstet G ynecol 1987, 94:932.

18. Saltiel C, Legendre, Grunfeld JP, et al.: Hemolytic uremic syndrome in association with pregnancy. In $\mathrm{H}$ emolytic U remic Syndrome and Thrombotic Thrombocytopenic Purpura. Edited by Kaplan BS, Trompeter RS, M oake JL. N ew York: M arcel Dekker; 1992:241-254.
19. Sibai BM, Kustermann L, Velasco J: Current understanding of severe preeclampsia, pregnancy-associated hemolytic uremic syndrome, thrombotic thrombocytopenic purpura, hemolysis, elevated liver enzymes, and low platelet syndrome, and postpartum acute renal failure: different clinical syndromes or just different names? Curr O pinion N ephrol Hypertens 1994, 3:436-445.

20. H ou S: Peritoneal dialysis and hemodialysis in pregnancy. Clin O bstet G ynaecol (Balliere) 1994, 8:491-510.

21. Davison JM : Pregnancy in renal allograft recipients: problems, prognosis, and practicalities. Clinc O bstet Gynaecol (Balliere) 1994, 8:511-535.

22. Douglas KA, Redman CW: Eclampsia in the United Kingdom. BM J 1994, 309:1395-1400.

23. Chesley LC, Annitto JE, Cosgrove RA: Pregnancy in the sisters and daughters of eclamptic women. Pathol M icrobiol 1961, 24:662.

24. Cooper DW, Brenneckes SP, Wilton AN : Genetics of pre-eclampsia. H ypertens Preg 1993, 12:1.

25. Khong TY, WF De, Robertson WB, Brosens I: Inadequate maternal vascular response to placentation in pregnancies complicated by preeclampsia and small for gestational age infants. $\mathrm{Br} J \mathrm{O}$ bstet Gynaecol 1986, 93:1049-1059.

26. Zhou Y, Fisher SJ, Janatpour M : H uman cytotrophoblasts adopt a vascular phenotype as they differentiate. A strategy for successful endovascular invasion? J Clin Invest 1997, 99:2139-2151.

27. Zhou Y, Damsky CH, Fisher S]: Preeclampsia is associated with failure of human cytotrophoblasts to mimic a vascular adhesion phenotype. O ne cause of defective endovascular invasion in this syndrome? J Clin Invest 1997, 99:2152-2164.

28. Lüscher TF, Dubey RK: Endothelium and platelet=derived vasoactive substances: role in the regulation of vascular tone and growth. In $\mathrm{H}$ ypertension: Pathophysiology, D iagnosis and M anagement, edn 2. N ew York: Raven Press; 1995: 609-630.

29. CLASP Collaborative Group. CLASP: A randomized trial of low-dose aspirin for the prevention and treatment of preeclampsia among 9364 pregnant women. Lancet 1994, 343:619-629.

30. Bucher HC, Guyatt GH, Cook RJ, et al.: Effect of calcium supplementation on pregnancy-induced hypertension and preeclampsia: a metaanalysis of randomized controlled trials. JAM A 1996, 275:1113-1117.

31. Hojo M, August P: Calcium metabolism in normal and hypertensive pregnancy. Semin N ephrol 1995, 15:504-511.

32. Levine RJ, H auth JC, Curet LB, et al.: Trial of calcium to prevent preeclampsia. N Engl J M ed 1997, 337:69-76.

33. A ugust $P$, Lenz $T$, Ales $K L$, et al.: Longitudinal study of the renin angiotensin system in hypertensive women: deviations related to the development of superimposed preeclampsia. A m J O bstet G ynecol $1990,163: 1612-1621$. 